\title{
Diferentes turnos de rega sobre o crescimento e produção de Macroptilium lathyroides (L.) Urb
}

\section{Different irrigation frequency on the growth and production of Macroptilium lathyroides (L.) Urb}

\author{
Mickson S. M. Silva ${ }^{1}$, Maria Socorro S. Carneiroํㅜ, Ricardo L. Edvan², Franklin E. M. Santiago3, \\ Júlio C. A. Nóbrega ${ }^{4}$ e Flávia L.A. Santiago ${ }^{5}$
}

\author{
${ }^{1}$ Departamento de Zootecnia, Universidade Federal do Ceará, Fortaleza, Ceará, Brasil; \\ ${ }_{2}^{2}$ Departamento de Zootecnia, Universidade Federal do Piauí, Bom Jesus, Piauí, Brasil; \\ ${ }^{3}$ Departamento de Engenharia Agronômica, Instituto Federal do Piauí, Uruçuí, Piauí, Brasil; \\ ${ }^{4}$ Centro de Ciências Agrárias, Ambientais e Biológicas, Universidade Federal do Recôncavo Baiano, Cruz das Almas, Bahia, Brasil; \\ ${ }^{5}$ Departamento de Ciência do Solo, Universidade Federal de Lavras, Lavras, Minas Gerais, Brasil. \\ ( ${ }^{\star} E$-mail: franklin.santiago@hotmail.com.br) \\ http://dx.doi.org/10.19084/RCA16099
}

Recebido/received: 2016.07.29

Recebido em versão revista/received in revised form: 2016.10.29

Aceite/accepted: 2016.10.31

\section{R E S U M O}

A utilização de espécies forrageiras nativas adaptadas às condições climáticas do semiárido brasileiro é uma alternativa para o aumento da produtividade da pecuária regional. Nesse sentido, objetivou-se com o presente trabalho avaliar as características de crescimento e produção de Macroptilium lathyroides (L.) Urb. quando submetido a diferentes turnos de rega. O delineamento experimental utilizado foi o de blocos casualizados, com cinco tratamentos e seis repetições, em que os tratamentos consistiram de cinco turnos de regas correspondentes aos intervalos de irrigação de 2, 4, 6, 8 e 10 dias. Não foi constatado efeito dos turnos de regas para a produção de serrapilheira. Para o número de folhas, observou-se um decréscimo de 30 para 11 folhas com o aumento dos turnos de rega. A produção de massa seca de forragem apresentou ajuste exponencial, com redução mais acentuada até o turno de rega de 4 dias. As demais variáveis decresceram linearmente com o aumento da frequência de irrigação. $\mathrm{O}$ aumento no intervalo dos turnos de rega promove reduções no crescimento e produção de Macroptilium lathyroides (L.) Urb., sendo o turno de rega de 2 dias o menos restritivo ao seu desenvolvimento.

Palavras-chave: défice hídrico, figo de pombo, forrageira nativa, herbáceo, leguminosa.

\section{A B S T R A C T}

The use of native forage species adapted to the climatic conditions of the Brazilian semiarid region is an alternative to increasing the regional livestock productivity. In this sense, the objective of the present study was to evaluate the growth characteristics and production of Macroptilium lathyroides (L.) Urb. when subjected to different irrigation frequency. The experimental design was a randomized complete block design with five treatments and six replications, where the treatments consisted of five irrigation shifts corresponding to the irrigation intervals 2, 4, 6, 8 and 10 days. It was not observed effect of watering shifts to produce litter. For the number of leaves, decrease fitting 30 for 11 sheets with increased irrigation interval. Dry matter production of forage presented exponential fit, with greater reduction to the 4 day irrigation schedule. The other variables linearly decreased with the increase in frequency of irrigation. The increase in the range of irrigation frequency promotes reduction in the growth and production of Macroptilium lathyroides (L.) Urb. The two days irrigation interval revealed as the least restrictive to their development.

Keywords: water stress, pigeon fig, native forage, herbaceous, legumes. 


\section{INTRODUÇÃO}

O figo de pombo (Macroptilium lathyroides (L.) Urb.) também conhecido como feijão-dos-arrozais ou feijão de rola é uma leguminosa de porte herbáceo, bem adaptada a regiões de clima quente e de baixas precipitações, regenera-se pelo banco de sementes do solo e é pouco exigente em fertilidade, vegetando em solos ácidos e mal drenados (Ferreira et al., 2004).

Nativa do Brasil, o figo de pombo encontra-se predominantemente distribuído no semiárido do nordeste brasileiro, região caracterizada por baixos e irregulares índices pluviométricos, com precipitação média anual em torno de 350 a $800 \mathrm{~mm}$ (Medeiros et al., 2005) que originam importantes limitações à atividade pecuária regional. É marcada, constantemente, por baixos índices de produtividade e rentabilidade, especialmente pelo fato das pastagens, que são a principal fonte alimentar para os animais, passarem por longos períodos de estiagem, prejudicando assim o acúmulo de forragem e o seu valor nutricional.

Os períodos de secas reduzem a disponibilidade de água no solo para as plantas, levando as mesmas a condições subótimas, culminado com o estresse hídrico. Na maioria das forrageiras a influência do estresse hídrico ocorre não apenas na produção e em sua qualidade (Santos et al., 2013), interfere também no seu metabolismo, que a depender da intensidade e da tolerância da mesma pode ocasionar a morte da planta (Xoconostle-Cazares et al., 2010).

As leguminosas constituem uma boa opção para melhorar o valor nutritivo das pastagens. É exemplo disso o figo de pombo, por possuir quantidades significativas de proteína bruta, fornecendo alimento com elevado valor nutricional para os animais. Entretanto, a adoção de leguminosas para a formação de pastagens, exclusivamente ou em consórcio, deve ser orientada de acordo com a espécie que mais se adapta às condições ambientais, para que possa produzir massa de forragem de boa qualidade apesar das condições adversas (Barcellos et al., 2008).

Desta forma, torna-se relevante realizar estudos sobre o comportamento de espécies nativas, como o figo de pombo, que apresenta grande potencial forrageiro sob condições de restrição hídrica no solo. Importa avaliar seus mecanismos adaptativos à seca e fornecer subsídios aos produtores na escolha da espécie mais adequada para esse tipo de ambiente, contribuindo para ganhos produtivos e manutenção da atividade pecuária regional.

Nesse contexto, objetivou-se com o presente trabalho avaliar o crescimento e produção do figo de pombo (Macroptilium lathyroides (L.) Urb.) quando submetido a diferentes turnos de rega.

\section{MATERIAL E MÉTODOS}

O experimento foi conduzido em casa de vegetação pertencente ao Departamento de Solos da Universidade Federal do Ceará (UFC), em Fortaleza (CE), no período de fevereiro a julho de 2013. As coordenadas geográficas do local do experimento são $03^{\circ} 43^{\prime} \mathrm{S}$ e $38^{\circ} 32^{\prime} \mathrm{W}$. Segundo a classificação de Köeppen, o clima é do tipo Aw, tropical chuvoso, com precipitações médias anuais em torno de $800 \mathrm{~mm}$ e temperatura média anual de $26,5^{\circ} \mathrm{C}$

O delineamento experimental utilizado foi o de blocos casualizados, com cinco tratamentos e seis repetições, em que os tratamentos consistiram de cinco turnos de regas correspondentes aos intervalos de irrigação de 2, 4, 6, 8 e 10 dias. A umidade do solo foi mantida a $80 \%$ da capacidade de campo e monitorada a cada intervalo estabelecido, conforme os tratamentos. Por meio da diferença de massa calculada do vaso no estado de capacidade de campo, determinada segundo metodologia adaptada de Bonfim-Silva et al. (2011) e da massa atual do vaso, era feita a reposição da umidade estabelecida.

As unidades experimentais consistiram de vasos plásticos preenchido com $5 \mathrm{dm}^{3}$ de amostras do horizonte A de um Argissolo Vermelho-Amarelo com textura arenosa (553 $\mathrm{g} \mathrm{kg}^{-1}$ de areia), apresentando as seguintes propriedades químicas, conforme metodologia de Raij et al. (2001): $\mathrm{pH}=6,0$; M.O. $=6,62 \mathrm{~g} \mathrm{~kg}^{-1} ; \mathrm{P}=13 \mathrm{mg} \mathrm{dm}^{-3} ; \mathrm{K}=0,08 \mathrm{cmol}_{c}$ $\mathrm{dm}^{-3} ; \mathrm{Ca}=1,00 \mathrm{cmol}_{\mathrm{c}} \mathrm{dm}^{-3} ; \mathrm{Mg}=0,9 \mathrm{cmol}_{\mathrm{c}} \mathrm{dm}^{-3} ; \mathrm{Al}=$ $0,10 \mathrm{cmol}_{\mathrm{c}} \mathrm{dm}^{-3} ; \mathrm{Na}=0,11 \mathrm{cmol}_{\mathrm{c}} \mathrm{dm}^{-3}$. 
Para a semeadura do figo de pombo (Macroptilium lathyroides (L.) Urb.) procedeu-se a quebra da dormência das sementes em água quente a $80^{\circ} \mathrm{C}$ por 60 segundos, conforme Vasconcelos et al. (2011). Em seguida, cada vaso recebeu vinte sementes, e dez dias após a germinação fez-se o desbaste, deixando apenas três plantas por vaso. Na ocasião do plantio, realizou-se a adubação com $150 \mathrm{mg} \mathrm{dm}^{-3}$ de superfosfato simples e $100 \mathrm{mg} \mathrm{dm}^{-3}$ de cloreto de potássio.

Aos 45 dias de crescimento foi realizado o corte de uniformização a $0,10 \mathrm{~m}$ da superfície do solo. A aplicação dos tratamentos experimentais teve início 21 dias após o corte de uniformização.

Aos 60 dias após o corte de uniformização, período em que as plantas floresceram e produziram vagens, foram avaliadas às seguintes variáveis: (a) altura da planta, aferida com uma régua graduada do nível do solo ao último trifólio; (b) diâmetro do caule, aferido com paquímetro digital a 0,05 $\mathrm{m}$ do solo; (c) número de folhas e brotos, por contagem direta; (d) massa seca de forragem total; (e) matéria seca (f) massa seca de raíz, obtidas por secagem em estufa de ventilação forçada a $65^{\circ} \mathrm{C}$ por 72 horas; (g) produção de serrapilheira e (h) número de nódulos.

Os dados do ensaio foram submetidos à análise de variância e regressão utilizando o sistema de análise estatística SISVAR, versão 5.3 (Ferreira, 2011).

\section{RESULTADOS E DISCUSSÃO}

Dentre as variáveis avaliadas, apenas a produção de serrapilheira não foi influenciada pelos turnos de rega, ficando evidente o efeito do déficit hídrico na diminuição das características de crescimento e produção do figo de pombo (Macroptilium lathyroides (L.) Urb.) (Figura 1).

Os turnos de rega promoveram decréscimo linear da altura da planta, tendo sido observada uma redução de 55,1\% na variável, com o aumento de 2 para 10 dias sem irrigação (Figura 1A). Vale ressaltar, que apesar do decréscimo no crescimento, fato já esperado, as plantas de figo de pombo não entraram em ponto de murcha permanente, demonstrando grande rusticidade e tolerância às condições de baixa umidade no solo.

O diâmetro do caule decresceu linearmente com o aumento dos turnos de rega, promovendo redução máxima de 42\% (Figura 1B). Segundo Turner (1997) quando as plantas são submetidas a restrições hídricas diminuem a turgescência das células o que, consequentemente, afeta os processos de expansão e divisão celular, ocorrendo uma paralisação no crescimento vegetal evidenciado na redução do alongamento da folha e do caule.

Quanto ao número de folhas, observou-se um decréscimo com ajuste exponencial convexo de 30 para 11 folhas com o espaçamento dos turnos de rega (Figura 1C). Quando o déficit hídrico atinge condições extremas, as plantas apresentam como respostas fisiológicas o decréscimo da produção da área foliar, fechamento dos estômatos e aceleração da senescência e da abscisão das folhas, traduzindo-se como uma estratégia de sobrevivência, para diminuir a área transpiracional (Lawn \& Likoswe, 2008; Taiz \& Zeiger, 2013). Observou-se, ainda, que a abscisão foliar prevaleceu em relação à senescência das folhas, provavelmente a planta submetida ao estresse hídrico produziu maior quantidade de etileno (abscisão e senescência) do que ácido abscísico (senescência). Tais resultados corroboram os de Correia \& Nogueira (2004), quando estudaram o efeito do déficit hídrico sobre o crescimento do amendoim (Arachis hypogaea L.) e observaram os mesmos efeitos.

Sob condições de déficit hídrico, o equilíbrio entre a produção de assimilados e a demanda para o desenvolvimento dos órgãos reprodutivos é severamente afetado pela redução na área foliar fotossinteticamente ativa (Marenco \& Lopes, 2005). Desta forma, o número de brotos foi reduzido linearmente em $47 \%$ com aumento dos turnos de rega de 2 para 10 dias sem irrigação (Figura 1D).

A produção de massa seca de forragem total apresentou decréscimo com ajuste exponencial, verificou-se uma redução mais acentuada até o turno de rega de 4 dias, permanecendo constante o acúmulo de biomassa com o aumento dos intervalos de irrigação (Figura 1E). A manutenção da taxa de acúmulo de assimilados é característica importante para a manutenção do potencial 
A.

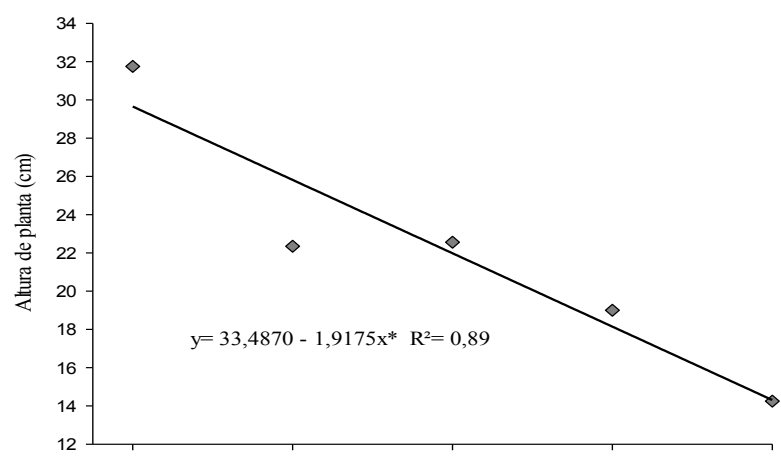

B.

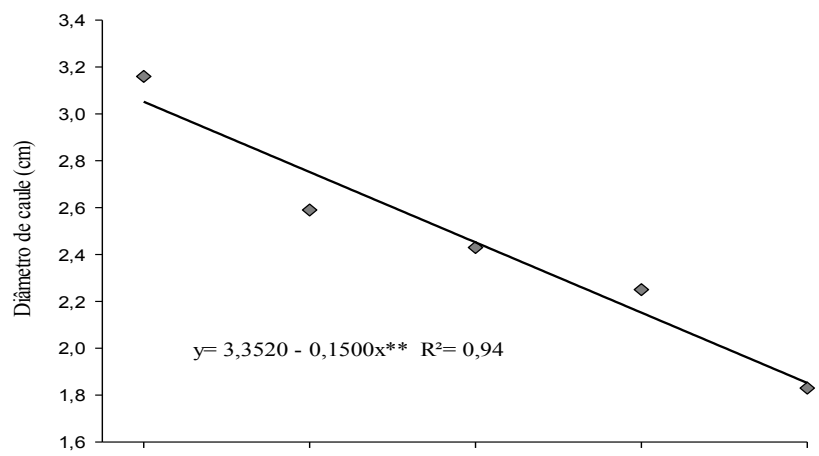

C.

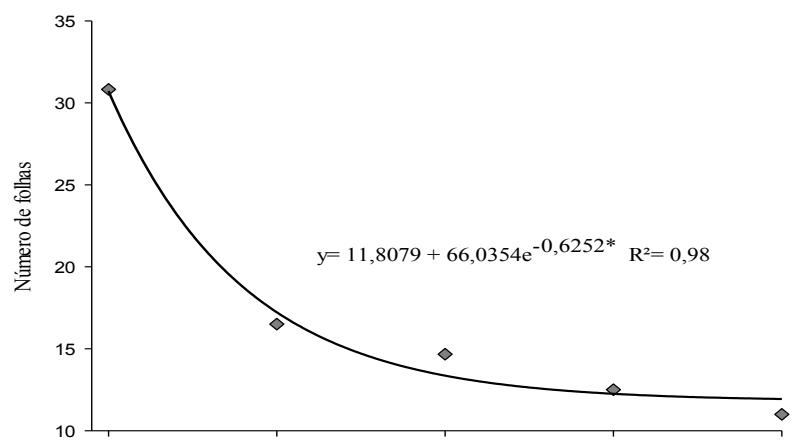

D.

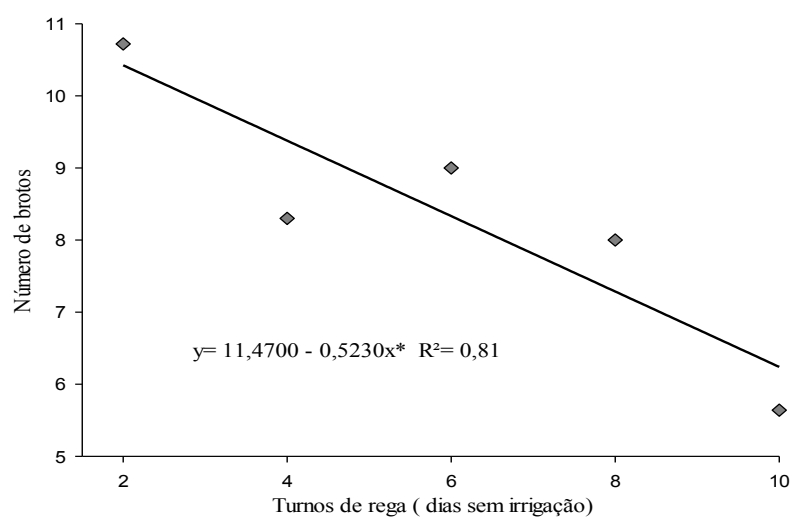

E.

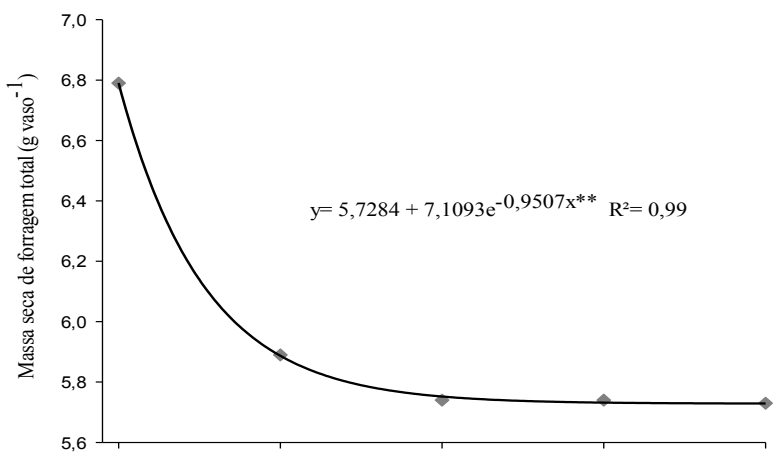

F.

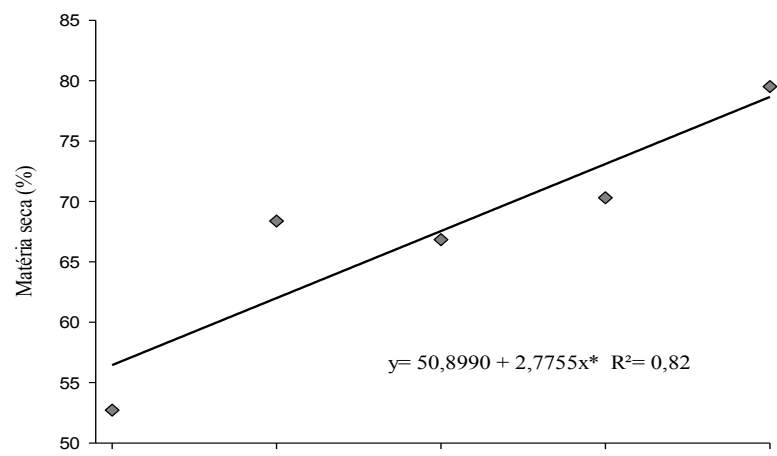

G.

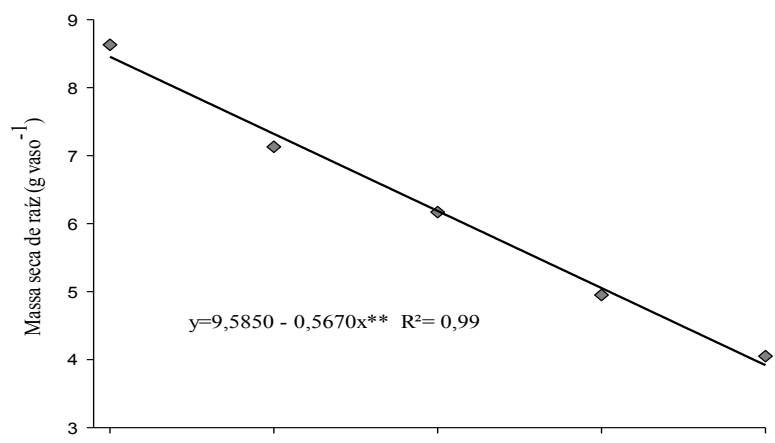

H.

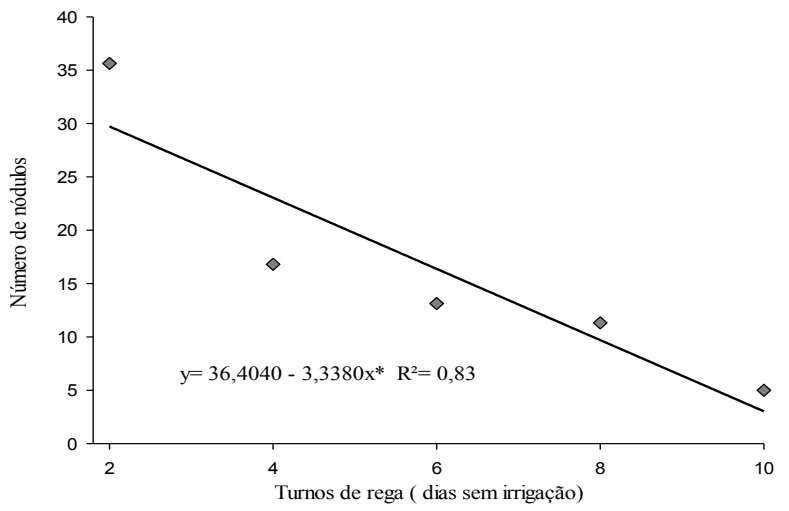

Figura 1 - Altura de planta (A), diâmetro de caule (B), número de folhas (C), número de brotos (D), massa seca de forragem total $(E)$, matéria seca $(F)$, massa seca de raíz $(G)$ e número de nódulos $(H)$ do figo de pombo (Macroptilium lathyroides (L.) Urb.) sob diferentes turnos de rega. ${ }^{*}(p<0,01)$ e $*(p<0,05)$ 
produtivo de plantas em condição de déficit hídrico (Lawn \& Likoswe, 2008). Desta forma, nota-se que para esta variável houve uma redução de apenas $15,6 \%$, ratificando a adaptação e capacidade produtiva do figo de pombo em condições ambientais adversas, como o de restrição hídrica. Fioreze et al. (2011) ao estudarem o comportamento de genótipos de soja (Glycine max (L.) Merr.) submetidos a déficit hídrico, verificaram significativa redução nos valores de massa seca.

Em relação à percentagem de matéria seca, como esperado, aumentou linearmente com os turnos de rega (Figura 1F). Ressalta-se que Gazolla-Neto et al. (2012) avaliando o encharcamento do solo para soja observaram que a planta teve seu teor de matéria seca reduzido devido ao excesso de umidade no solo. Esse fato demonstra que tanto o excesso como o déficit hídrico prejudicam o acúmulo de água na planta.

A massa seca da raíz decresceu linearmente com o aumento dos turnos de rega, obtendo uma redução máxima de $53 \%$, do turno de rega de 2 para 10 dias (Figura 1G). Em resposta a baixa disponibilidade de água no solo, há um estímulo à expansão do sistema radicular para zonas mais profundas e úmidas, podendo ser entendido como um importante mecanismo de adaptação para algumas espécies. Correia \& Nogueira (2004) obtiveram maiores médias de massa seca de raíz em amendoim sob o tratamento com suspensão total de rega. Este comportamento não foi observado no presente estudo, assim como nos resultados obtidos por Costa et al. (1997), que constataram reduções na área foliar, na matéria seca da parte aérea e das raízes ao estudar o efeito do déficit hídrico na produção, componentes de produção e distribuição de raízes no caupi (Vigna unguiculata (L) Walp). Tal como observado em diversos trabalhos, este fato dependerá da intensidade e duração do déficit de água, uma vez que parecem ser as raízes menos sensíveis à estresse hídrico, quando comparadas à parte aérea (Leite \& Virgens Filho, 2004).

Algumas plantas adaptadas a regiões áridas e semiáridas apresentam mecanismos de reciclagem de raiz elevado ao menor sinal de estresse hídrico, Edvan et al. (2013) estudaram o enraizamento da palma forrageira (Opuntia ficus-indica Mill) em regiões semiáridas do Brasil e concluíram que no período de estiagem essa planta reduz a quantidade de raiz rapidamente para evitar perdas para o solo, e nas primeiras chuvas ocorre uma rápida reposição radicular.

O número de nódulos encontrados nas raízes do figo de pombo reduziu-se linearmente em $63,4 \%$ (Figura $1 \mathrm{H}$ ), fato esperado, uma vez a deficiência hídrica pode afetar a nodulação e a atividade da nitrogenase em leguminosas (Streeter, 2003). Efeitos deletérios propiciados pela diminuição do conteúdo de água no solo sobre a fixação biológica de nitrogênio são relatados em outros trabalhos (Chalk et al., 2010; Zilli et al., 2013).

\section{CONCLUSÕES}

O aumento no intervalo dos turnos de rega promove reduções no crescimento e produção do figo de pombo (Macroptilium lathyroides (L.) Urb.), sendo o turno de rega de dois dias o menos restritivo ao seu desenvolvimento.

\section{REFERÊNCIAS BIBLIOGRÁFICAS}

Barcellos, A.O.; Ramos A.K.D.; Vilela, L. e Martha Junior, G.B. (2008) - Sustentabilidade da produção animal baseada em pastagens consorciadas e no emprego de leguminosas exclusivas, na forma de banco de proteína, nos trópicos brasileiros. Revista Brasileira de Zootecnia, vol. 37, p. 51-67. http://dx.doi.org/10.1590/ $\underline{\text { S1516-35982008001300008 }}$

Bonfim-Silva, E.M.; Silva, T.J.A.; Cabral, C.E.A.; Kroth, B.E. e Rezende, D. (2011) - Desenvolvimento inicial de gramíneas submetidas ao estresse hídrico. Revista Caatinga, vol. 24, n. 2, p. 180-186.

Chalk, P.M.; Alves, B.J.R.; Boddey, R.M. e Urquiaga, S. (2010) - Integrated effects of abiotic stresses on inoculant performance, legume growth and symbiotic dependence estimated by ${ }^{15} \mathrm{~N}$ dilution. Plant and Soil, vol. 328, n. 1, p. 1-16. http://dx.doi.org/10.1007/s11104-009-0187-7 
Correia, K.G. e Nogueira, R.J.M.C. (2004) - Avaliação do crescimento do amendoim (Arachis hypogaea L.) submetido a déficit hídrico. Revista de Biologia e Ciências da Terra, vol. 4, n. 2, p. 112-117.

Costa, M.M.M.N.; Távora, F.J.A.F.; Pinho, J.L.N. e Melo, F.I.O. (1997) - Produção, componentes de produção, crescimento e distribuição das raízes de caupi submetido à deficiência hídrica. Pesquisa Agropecuária Brasileira, vol. 32, n. 1, p. 43-50.

Edvan, R.L.; Fernades, P.D.; Carneiro, M.S.S.; Neder, D.G.; araujo, J.S.; Andrade, A.P. e Souto Filho, L.T. (2013) - Acúmulo de biomassa e crescimento radicular da palma forrageira em diferentes épocas de colheita. Revista Acadêmica de Ciências Agrária e Ambiental, vol. 11, n. 4, p. 35-43. http://dx.doi.org/10.7213/academico.011.004.AO04

Ferreira, D.F. (2014) - Sisvar: A guide for its bootstrap procedures in multiple comparisons. Ciência e Agrotecnologia, vol. 38, n. 2, p. 109-112. http://dx.doi.org/10.1590/S1413-70542014000200001

Ferreira, O.G.L.; Monks, P.L.; Machado, A.N. e Affonso, A.B. (2004) - Efeito do corte da parte aérea e de épocas de colheita sobre o rendimento e qualidade das sementes de feijão-dos arrozais. Revista Brasileira de Agrociência, vol. 10, n. 2, p. 175-178.

Fioreze, S.L.; Pivetta, L.G.; Fano, A.; Machado, F.R. e Guimarães, V.F. (2011) - Comportamento de genótipos de soja submetidos a déficit hídrico intenso em casa de vegetação. Revista Ceres, vol. 58, n. 3, p. 342-349. http://dx.doi.org/10.1590/S0034-737X2011000300015

Gazolla-Neto, A.; Aumonde, T.Z.; Pedó, T.; Olsen, D. e Villela, F.A. (2012) - Níveis de umidade do solo de várzea e seus efeitos sobre a emergência e crescimento inicial de plântulas de soja. Informativo ABRATES, vol. 22, p. 28-31.

Lawn, R.J. e Likoswe, A.A. (2008) - Genotypic differences in leaf area maintenance contribute to differences in recovery from water stress in soybean. Australian Journal of Agricultural Research, vol. 59, n. 12, p. 1075-1085. http://dx.doi.org/10.1071/AR08177

Leite, M.L. e Virgens Filho, J.S.V. (2004) - Produção de matéria seca em plantas de Caupi (Vigna unguiculata (L.) Walp) submetidas a déficits hídricos. Ciências Agrárias e Engenharias, vol. 10, n. 1, p. 43-51. http://dx.doi. org/10.5212/publicatio.v10i01.820

Marenco, R.A. e Lopes, N.F. (2005) - Fisiologia vegetal: fotossíntese, respiração, relações hídricas e nutrição mineral. UFV, Viçosa, MG, $451 \mathrm{p}$.

Medeiros, S.S; Cecilio, R.A.; Melo Junior, J.C.F. e Silva Junior, J.L.C. (2005) - Estimativa e especialização das temperaturas do ar mínimas, médias e máximas na região nordeste do Brasil. Revista Brasileira de Engenharia Agrícola e Ambiental, vol. 9, n. 2, p. 247-255. http://dx.doi.org/10.1590/\$1415-43662005000200016

Raij, B.; Andrade, J.C.; Cantarella, H. e Quaggio, J.A. (2001) - Análise química para avaliação de fertilidade do solo. Campinas: Instituto Agronômico de Campinas, São Paulo, SP, 285 p.

Santos, P.M.; Cruz, P G.; Araújo, L.C.; Pezzopane, J.R.M.; Valle, C.B. e Pezzopane, C.G. (2013) - Response mechanisms of Brachiaria brizantha cultivars to water déficit stress. Revista Brasileira de Zootecnia, vol. 42, n. 11, p. 767-773. http://dx.doi.org/10.1590/S1516-35982013001100001

Streeter, J.G. (2003) - Effects of drought on nitrogen fixation in soybean root nodules. Plant, Cell and Environment, vol. 26, n. 8, p. 1199-1204. http://dx.doi.org/10.1046/j.1365-3040.2003.01041.x

Taiz, L. e Zeiger, E. (2013) - Fisiologia vegetal. 5. ed. Porto Alegre, Artmed, 819 p.

Turner, N.C. (1997) - Further progress in crop water relations. Advances in Agronomy, vol. 58, n. 1, p. 293-338. http://dx.doi.org/10.1016/S0065-2113(08)60258-8

Vasconcelos, W.A.; Santos, E.M.; Andrade, A.P.; Bruno, R.L.A. e Edvan, R.L. (2011) - Germinação de sementes e desenvolvimento de plântulas de figo de pombo (Macroptilium lathyroides). Revista Trópica - Ciências Agrárias e Biológicas, vol. 5, n. 1, p. 3-11.

Xoconostle-Cazares, B.; Ramirez-Ortega, F.A.; Flores-Elene, L. e Ruiz-Medrano, R. (2010) - Drought tolerance in crop plants. American Journal of Plant Physiology, vol. 5, n. 5, p. 241-256. http://dx.doi.org/10.3923/ ajpp.2010.241.256

Zilli, J.E.; Pereira, G.M.D.; França Júnior, I.; Silva, K.; Hungria, M. e Rouws, J.R.C. (2013) - Dinâmica de rizóbios em solo do cerrado de Roraima durante o período de estiagem. Acta Amazônica, vol. 43, n. 2, p. 153-160. 